\title{
Is the number of trocars important in laparoscopic cholecystectomy?
}

\author{
Münevver Moran, ${ }^{1}$ M. Mahir Özmen, ${ }^{1,2}$ İsmail Bilgiç, ${ }^{1,3}$ Hayrettin Dizen, ${ }^{1,4}$

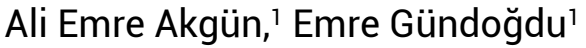 \\ 'Department of General Surgery, Ankara Numune Teaching and Research Hospital, Ankara, Turkey \\ ${ }^{2}$ Department of General Surgery, Hacettepe University Faculty of Medicine, Ankara, Turkey \\ ${ }^{3}$ Department of General Surgery, Turgut Ozal University Faculty of Medicine, Ankara, Turkey \\ ${ }^{4}$ Yunus Emre Hospital, Eskisehir, Turkey
}

\begin{abstract}
Introduction: Laparoscopic cholecystectomy (LC) is the criterion standard for cholelithiasis. There have been some changes in LC technique, one of which was a reduction in the number of trocars used. The aim of the present study was to explore the feasibility of reducing the number of ports in cases of LC without compromising safety, and to evaluate the benefits associated in terms of pain, recovery, and patient satisfaction.

Materials and Methods: Sixty adults with symptomatic cholelithiasis were enrolled in this study, and patients were divided into 4 equal groups of 15 . During the operation, 1- (single incision laparoscopic surgery [SILS]), 2-, 3-, or 4-trocar LC was performed. For the assessment, the following parameters were compared: operating time, success rate, visual analogue pain score, requirement for analgesia (diclofenac), complications, patient satisfaction score with respect to operation and scars, and length of postoperative hospital stay.

Results: There were 45 female ( $75 \%)$ and 15 male (25\%) patients with median age of 42.8 years (range: 20 62 years). Demographic data (age, sex, body mass index) were similar in all groups. The 3- and 4-trocar groups had significantly shorter mean operating time than the other groups (SILS: $50 \pm 14$ minutes; 2-trocar: $36 \pm 10$ minutes; 3 -trocar: $27 \pm 10$ minutes; 4 -trocar: $24 \pm 7$ minutes; $p=0.01$ ). There was no instance of bile duct injury or intra-abdominal collection in any group. One patient in SILS group developed cholangitis, and 1 one patient in 3-trocar group developed wound infection postoperatively that improved with conservative treatment. There was no difference in terms of analgesia requirement, mean overall pain score, overall satisfaction score, or length of hospital stay between the 4 groups. Scar satisfaction score was significantly higher in SILS and 2-trocar groups compared with the others.

Conclusion: It appears that SILS and 2-port techniques are as reliable as 3-port and 4-port methods, with no obvious increase in bile duct injury, and although use of these techniques did not reduce need for analgesia, it did increase patient satisfaction.
\end{abstract}

Keywords: Laparoscopic cholecystectomy; single incision laparoscopic surgery; trocar number. 


\section{Introduction}

Laparoscopic cholecystectomy (LC) is the gold standard for gallbladder removal and the most common laparoscopic surgical procedure in the world. ${ }^{[1-3]}$ During the era of laparoscopic surgery, less postoperative pain and early recovery were major goals for achieving better patient care and cost-effectiveness. Hence, there have been some changes in the LC technique. One development was a reduction in the number of trocars. ${ }^{[1-4]}$ Single incision laparoscopic surgery (SILS) was described as early as 1992 by Pelosi and Pelosi, ${ }^{[5]}$ who performed a single-puncture laparoscopic appendectomy, and in 1997 by Navarra et al., ${ }^{[6]}$ who performed a LC via two transumbilical trocars and three transabdominal gallbladder stay sutures.

A prospective randomized controlled clinical study was performed to explore the feasibility of reducing the port number without compromising safety in LC, and the real benefit associated with it in terms of pain, recovery, and patient satisfaction was evaluated.

\section{Materials and Methods}

Between February and December 2009, 60 adults with symptomatic cholelithiasis were enrolled in this study. Patients were randomized by the clinic secretary with protocol numbers, and divided into four equal groups of 15 patients each. We prospectively recruited consecutive patients aged 20-69 years who were admitted for elective LC. Exclusion criteria included patients with acute cholecystitis with gallbladder empyema and those who were not fit for laparoscopic surgery on anesthetic grounds. All procedures were performed by experienced specialist laparoscopic surgeons who had performed more than 500 conventional LCs. All patients provided a signed informed consent for the randomization and procedure.

\section{Surgical Technique}

The patients were placed in the supine position. Conventional laparoscopic instruments and a $30^{\circ}$ laparoscope with a $10 \mathrm{~mm}$ diameter were used during the cholecystectomy. A $(10 \mathrm{~mm})$ trocar for the video laparoscope was placed at the infraumbilical region by open technique, and then a $10 \mathrm{~mm}$ subxiphoid port and two $5 \mathrm{~mm}$ subcostal ports were placed in the four-port LC. Trocar localizations are shown in Figure 1. In the three-port LC, a $10 \mathrm{~mm}$ infraumbilical port, $10 \mathrm{~mm}$ subxiphoid, and $5 \mathrm{~mm}$ subcostal port were used. In the two-port LC, a $10 \mathrm{~mm}$ infraumbilical port and $10 \mathrm{~mm}$ subxiphoid port were used (Figure
2). In the single incision (SILS) group, a subumbilical or transumbilical $2-2.5 \mathrm{~cm}$ incision was made, the peritoneum was opened under direct vision, a $10 \mathrm{~mm}$ trocar was inserted, and pneumoperitoneum was established. The laparoscope was inserted, and a further one or two trocars were inserted through the fascia adjacent to the camera port (Figure 3). In two patients in the SILS group, we used three-channel ports developed for this purpose (SILS ${ }^{\text {TM }}$ Port, Covidien, Norwalk, CT, USA). In the SILS and two-trocar groups, if needed, two or three straight-needle

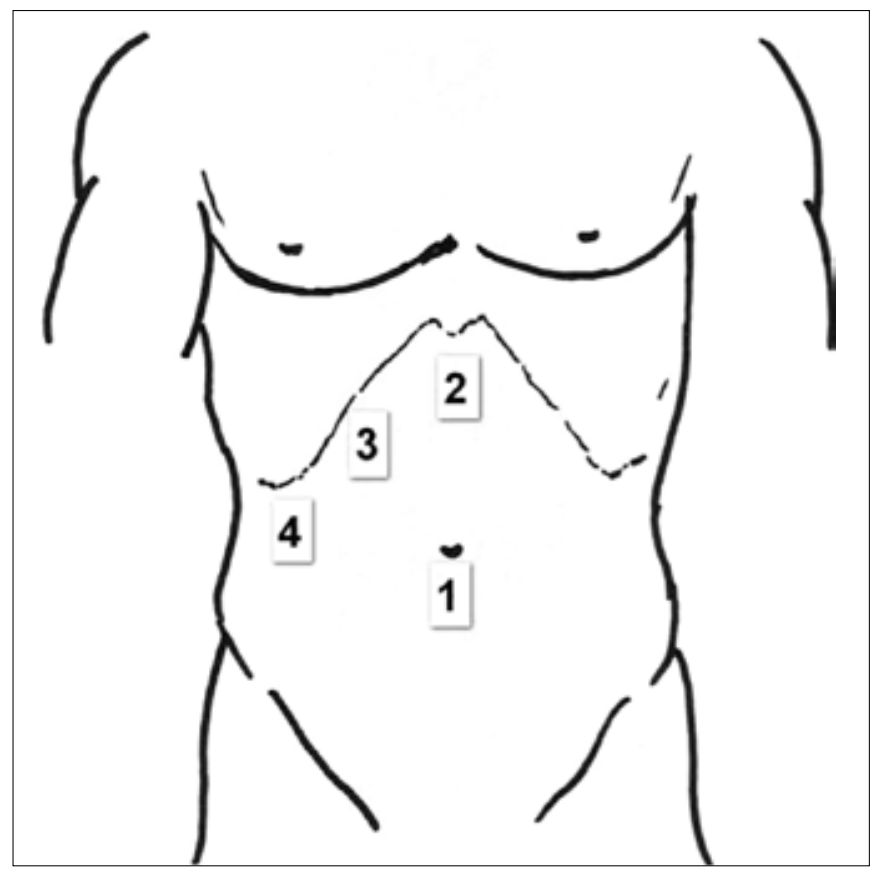

Figure 1. Trocar localizations. 1: Single incision; $1+2$ : two trocars; $1+2+3$ : three trocars; $1+2+3+4$ : four trocars.

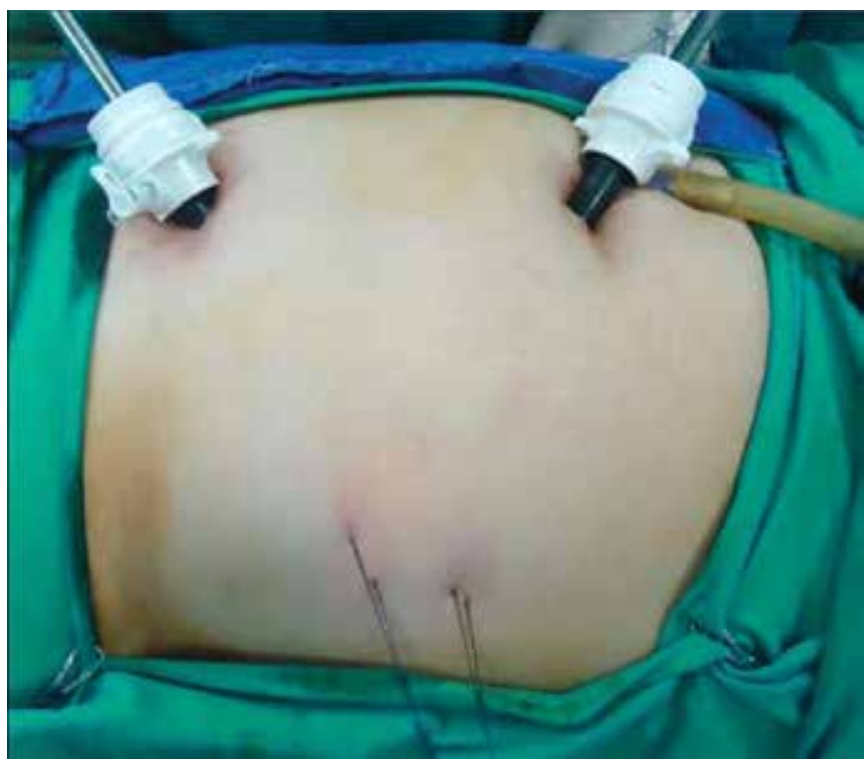

Figure 2. Two-port laparoscopic cholecystectomy. 


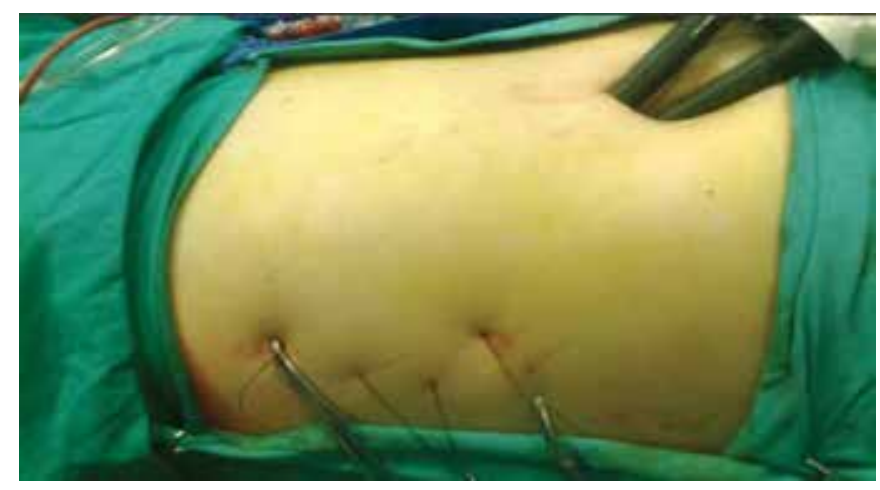

Figure 3. SILS cholecystectomy with two trocars.

sutures were passed through the gallbladder fundus, near the infundibulum, and the gallbladder was suspended on the right subcostal abdominal wall, exposing the Calot's triangle. The fundus was pushed cranially to demonstrate the desired exposure of the undersides of the gallbladder and liver. The cystic duct and cystic artery were identified, doubly clipped by a $10 \mathrm{~mm}$ multiple clip applicator, and divided in the conventional manner. Dissection of the gallbladder off the liver bed was performed with hook diathermy or laparoscopic scissors. Following complete dissection and excision of the gallbladder, the suspension stitches were removed, and the gallbladder was retrieved through the subxiphoid or umbilical incision in a standard fashion. The abdominal wall fascia was closed using nonabsorbable sutures [Prolene (Ethicon)], and the skin was closed using absorbable or nonabsorbable sutures [e.g., 3/0 Vicryl (Ethicon), 3/0 Prolene (Ethicon)].

\section{Postoperative Evaluation and Follow-Up}

Intramuscular injection of diclofenac $50 \mathrm{mg}$ was given every 8 hours for the first 24 hours for postoperative pain control. Patients were discharged on the first or second postoperative day if they had satisfactory pain control and were able to tolerate their usual diet. In case of intolerable pain, inability to consume a normal diet, or any other problem, discharge was delayed until recovery. All wound dressings were kept intact until the first follow-up at one week after surgery.

For the assessment, the following parameters were compared: operative time, success rate, visual analogue scale (VAS) pain score, number of analgesic injections (diclofenac), complications, patient satisfaction score with respect to the operation and scars, and postoperative hospital stay. The operative time was recorded from the beginning of the insuffl ation until closure of the final wound. To ensure the blind nature of the study, an inde- pendent physician unaware of the procedures assessed the pain score by using a $10 \mathrm{~mm}$ unscaled VAS after 12 hours and on the first postoperative day, and analgesia requirements after surgery were recorded. Patient satisfaction scores with respect to operation and scars were reviewed one week after surgery by an independent physician using a $10 \mathrm{~cm}$ unscaled VAS ( 0 , unsatisfied; 10 , very satisfied). These assessments were performed by an independent specialist surgeon who was unaware of group assignments regarding the type of surgery.

\section{Statistical Analysis}

The Statistical Package for the Social Sciences (SPSS) version 15.0 (Chicago, IL, USA) for Windows was used for statistical analysis. Kruskal-Wallis test was used to evaluate the significance of each parameter. For analysis of the VAS scores between two groups, the Mann-Whitney U test was used. A p value $<0.05$ was considered statistically significant.

\section{Results}

From February 2009 to October 2009, 60 consecutive patients were recruited for the present study. There were 45 female (75\%) and 15 male (25\%) patients, with a median (range) age of 43 (20-62) years. The demographic data (age, sex, body mass index) were similar in all groups (Table 1). LC was performed uneventfully in all patients and none required conversion to an open procedure or a conventional LC in the other groups. In terms of outcome, the success rate was the same in all groups.

The mean operation time was different between the groups. The three- and four-trocar groups had a significantly shorter mean operative time than the others (SILS $50.4 \pm 14.3 \mathrm{~min}$, 2-trocar $36 \pm 10.5 \mathrm{~min}$, 3-trocar $27.6 \pm 10.6 \mathrm{~min}$, and 4-trocar $24.2 \pm 7.2 \mathrm{~min} ; \mathrm{p}=0.01$ ). However, there was no statistically significant difference in the operating time for the SILS vs two-trocar groups ( $\mathrm{p}=0.07$ ) or for the three-trocar vs four-trocar groups ( $\mathrm{p}=0.345)$.

There were no bile duct injuries or intraabdominal collections in any group. One patient in the SILS group developed cholangitis and one patient in the three-trocar group developed wound infection postoperatively that improved with conservative treatment.

The mean overall pain score was similar in the four groups. VAS pain scores in the postoperative period at 12 hours were $6.2,5.9,5.8$, and $6.4(\mathrm{p}=0.586)$ and at 24 hours 
Table 1. Demographic data, complications and patient outcomes

\begin{tabular}{lccccc} 
& $\begin{array}{c}\text { Single incision } \\
(\mathbf{n}=\mathbf{1 5})\end{array}$ & $\begin{array}{c}\text { 2-trocars } \\
(\mathbf{n}=\mathbf{1 5})\end{array}$ & $\begin{array}{c}\text { 3-trocars } \\
(\mathbf{n}=\mathbf{1 5})\end{array}$ & $\begin{array}{c}\text { 4-trocars } \\
(\mathbf{n}=\mathbf{1 5})\end{array}$ & $\mathbf{p}$ \\
\hline Age (years) & $37.6 \pm 9.04$ & $41.7 \pm 9.8$ & $45.2 \pm 12$ & $42.8 \pm 8.3$ & 0.105 \\
Sex (female/male) & $3 / 12$ & $2 / 13$ & $3 / 12$ & $5 / 10$ & 0.492 \\
Body mass index $\left(\mathrm{kg} / \mathrm{m}^{2}\right)$ & $30.9 \pm 4.1$ & $29.8 \pm 4.2$ & $30.8 \pm 5.6$ & $30.6 \pm 5.6$ & 0.907 \\
Operation time & $50.4 \pm 14.3$ & $37.6 \pm 9.7$ & $27.6 \pm 10.6$ & $24.2 \pm 7.2$ & 0.001 \\
Complications & 1 (cholangitis) & - & 1 (wound infection) & - & \\
Mean pain scores (12 hour) & $6.2 \pm 1.4$ & $5.9 \pm 1.4$ & $5.8 \pm 2$ & $6.4 \pm 1.1$ & 0.586 \\
Mean pain scores (24 hour) & $4.9 \pm 1.3$ & $4.3 \pm 1.4$ & $4.3 \pm 1.3$ & $4.5 \pm 1.3$ & 0.604 \\
No. of analgesic injections & $1.9 \pm 0.4$ & $2 \pm 0.5$ & $1.7 \pm 0.7$ & $2 \pm 0.2$ & 0.251 \\
Mean satisfaction scores & $8.4 \pm 1.3$ & $7.2 \pm 1.3$ & $7.4 \pm 1.1$ & $7.2 \pm 1.2$ & 0.067 \\
Mean scar satisfaction scores & $9 \pm 1$ & $8.8 \pm 1$ & $7.7 \pm 1$ & $8.2 \pm 1.3$ & 0.001 \\
Hospital stay & $1.5 \pm 1.1$ & $1.3 \pm 0.7$ & $1.3 \pm 0.6$ & $1.2 \pm 1$ & 0.567
\end{tabular}

were 4.9, 4.3, 4.3, and 4.5 ( $\mathrm{p}=0.604)$ in the SILS, twoport, three-port and four-port groups, respectively. There was also no difference in terms of analgesia requirements between the four groups $(\mathrm{p}=0.251)$. The hospital stay was similar in all groups $(\mathrm{p}=0.567)$.

Overall satisfaction scores among the groups did not reach significant differences $(\mathrm{p}=0.067)$. The satisfaction score of patients in terms of scarring was significantly higher in the SILS and two-trocar groups than the others $(\mathrm{p}=0.025)$.

\section{Discussion}

The first LC was performed in 1987 by Phillip Mouret, and it was later established by Dubois and Perissat in 1990. ${ }^{[7,8]}$ In recent years, laparoscopic surgery has developed rapidly. During the era of laparoscopic surgery, less postoperative pain and early recovery have been the major goals for achieving better patient care and cost-effectiveness. Hence, there have been a number of modifications in the LC technique. Usually, the standard LC is done using four or three trocars. Today, we stand on the brink of a technological explosion that may drive surgery from requiring small incisions to being incisionless. ${ }^{[1-6,9-24]}$ To date, there has not been any randomized prospective controlled study comparing the single incision vs. two- vs. three- vs. fourport techniques.

Ramachandran ${ }^{[24]}$ performed two-trocar LC using two incisions and three transabdominal stay sutures. Navarra et al. ${ }^{[6]}$ performed the first SILS cholecystectomy in 1997 using two $10 \mathrm{~mm}$ trocars and three transabdominal stay sutures to aid in gallbladder retraction. Piskun and Ra- jpal ${ }^{[10]}$ described the use of two $5 \mathrm{~mm}$ trocars and two stay sutures in 1999. In both methods, the two trocars were inserted through the umbilicus, with a bridge of fascia between them, and were used for a camera and a working instrument, respectively. SILS limits the number of ports that can be used through a single incision, and a single port with multiple instruments restricts their degrees of movement. Proximity of instruments when used through a single port often results in inadequate retracting abilities and loss of triangulation, which may lead to suboptimal exposure of Calot's triangle. Dislodgement of single large tri-ports or multiple small ports through a single incision is another potential problem that may cause loss or leakage of pneumoperitoneum, thereby risking mishap. ${ }^{[13]}$ A rare but potentially serious postoperative complication of abdominal surgery (including LC) is incisional hernia. These usually occur at larger ports $(10 \mathrm{~mm})$, especially at the umbilicus, and an important factor leading to the development of portsite hernia is inadequate closure of the abdominal fascia at the port sites. Exertion of pressure by a single large port or multiple ports at a single site may potentially weaken the fascia, thereby increasing the risk of hernias, especially on intentional creation of a "Swiss cheese" defect. ${ }^{[14,17]}$

Incisional pain after LC has been found to dominate over visceral and shoulder pain in both incidence and intensity in the first week postoperatively. ${ }^{[25]}$ Several studies have demonstrated that less postoperative pain is associated with a reduction in either size or number of trocars. ${ }^{[18,19,22,24]}$ However, other studies have claimed that the diminished port technique did not reduce the overall pain score or 
analgesia requirement. . $^{[1,3,9,20,21,26,27]}$ In the current study, we failed to demonstrate any difference in terms of overall pain score 12 and 24 hours after surgery or in analgesic requirements among the four groups.

Mean operative time was shorter in the four-port and threeport LC groups, which does correlate with some previous studies.

Studies and meta-analyses comparing three versus four trocars showed that there was no significant difference in operating time, success rate, analgesia requirements, or postoperative hospital stay between the three- and fourport LC groups. ${ }^{[9,19,22]}$ We know that the incidence rate of major complications (common bile duct and major vessel injury) following three- or four-trocar LC is well documented and is $<1 \%$, with an overall complication rate of $\leq 3 \%$. ${ }^{[1,12]}$ Some surgeons have expressed concerns about the safety of the diminished port technique, arguing that it may lead to a higher incidence of bile duct injuries and complications, ${ }^{[18,23]}$ but others failed to confirm this. $[1,10,15,19,20,22,27]$ Our study did not reveal that a reduced number of ports is associated with an increase in complications.

The present study revealed that the mean operation time was different in the four groups. The three- and four-trocar groups had a significantly shorter mean operative time than the others. In this study, the four groups were similar in success rate and postoperative hospital stay. It was also found that the three-port, two-port and SILS method did not reduce the requirement of analgesia, which was similar to that of the four-port technique. Most of our patients in all groups reported high satisfaction with the surgery and the surgical scars. Although a higher overall satisfaction score was observed for the SILS and two-port LC groups, the difference did not reach statistical significance. However, the scar satisfaction score was significantly higher in the SILS and two-trocar groups compared to the others.

In conclusion, it appears that the SILS and two-port techniques are as reliable as the three- and four-port techniques, with no obvious increase in complications and better patient satisfaction.

\section{References}

1. Cerci C, Tarhan OR, Barut I, Bülbül M. Three-port versus fourport laparoscopic cholecystectomy. Hepatogastroenterology 2007;54:15-6.
2. Welter FH. Laparoscopic cholecystectomy-a never-ending success story?. MMW Fortschr Med 2006;148:38-9.

3. Tacchino R, Greco F, Matera D. Single-incision laparoscopic cholecystectomy: surgery without a visible scar. Surg Endosc 2009;23:896-9.

4. Lee KW, Poon CM, Leung KF, Lee DW, Ko CW. Two-port needlescopic cholecystectomy: prospective study of 100 cases. Hong Kong Med J 2005; 1 1:30-5.

5. Pelosi MA, Pelosi MA 3rd. Laparoscopic appendectomy using a single umbilical puncture (minilaparoscopy). J Reprod Med 1992;37:588-94.

6. Navarra G, Pozza E, Occhionorelli S, Carcoforo P, Donini I. One-wound laparoscopic cholecystectomy. Br J Surg 1997;84:695.

7. Dubois F, Icard P, Berthelot G, Levard H. Coelioscopic cholecystectomy. Preliminary report of 36 cases. Ann Surg 1990;211:60-2.

8. Litynski GS. Profiles in laparoscopy: Mouret, Dubois, and Perissat: the laparoscopic breakthrough in Europe (19871988). JSLS 1999;3:163-7.

9. Sun S, Yang K, Gao M, He X, Tian J, Ma B. Three-port versus four-port laparoscopic cholecystectomy: meta-analysis of randomized clinical trials. World J Surg 2009;33:1904-8.

10. Piskun G, Rajpal S. Transumbilical laparoscopic cholecystectomy utilizes no incisions outside the umbilicus. J Laparoendosc Adv Surg Tech A 1999;9:361-4.

11. Tuveri M, Tuveri A. Laparoscopic cholecystectomy: complications and conversions with the 3-trocar technique: a 10-year review. Surg Laparosc Endosc Percutan Tech 2007;17:3804.

12. Varadarajulu S, Tamhane A, Drelichman ER. Patient perception of natural orifice transluminal endoscopic surgery as a technique for cholecystectomy. Gastrointest Endosc 2008;67:854-60.

13. Romanelli JR, Mark L, Omotosho PA. Single port laparoscopic cholecystectomy with the TriPort system: a case report. Surg Innov 2008;15:223-8.

14. Merchant AM, Cook MW, White BC, Davis SS, Sweeney JF, Lin E. Transumbilical Gelport access technique for performing single incision laparoscopic surgery (SILS). J Gastrointest Surg 2009;13:159-62.

15. Navarra G, La Malfa G, Bartolotta G, Currò G. The invisible cholecystectomy: a different way. Surg Endosc 2008;22:2103.

16. Cuesta MA, Berends F, Veenhof AA. The "invisible cholecystectomy": A transumbilical laparoscopic operation without a scar. Surg Endosc 2008;22:1211-3.

17. Alptekin H, Yilmaz H, Acar F, Kafali ME, Sahin M. Incisional hernia rate may increase after single-port cholecystectomy. J Laparoendosc Adv Surg Tech A 2012;22:731-7.

18. Kurpiewski W, Pesta W, Kowalczyk M, Głowacki L, Juśkiewicz W, Szynkarczuk R, et al. The outcomes of SILS cholecystectomy in comparison with classic four-trocar laparoscopic cholecystectomy. Wideochir Inne Tech Maloinwazyjne 2012;7:286-93.

19. Trichak S. Three-port vs standard four-port laparoscopic 
cholecystectomy. Surg Endosc 2003;17:1434-6.

20. Hao L, Liu M, Zhu H, Li Z. Single-incision versus conventional laparoscopic cholecystectomy in patients with uncomplicated gallbladder disease: a meta-analysis. Surg Laparosc Endosc Percutan Tech 2012;22:487-97.

21. Poon CM, Chan KW, Lee DW, Chan KC, Ko CW, Cheung HY, et al. Two-port versus four-port laparoscopic cholecystectomy. Surg Endosc 2003;17:1624-7.

22. Kumar M, Agrawal CS, Gupta RK. Three-port versus standard four-port laparoscopic cholecystectomy: a randomized controlled clinical trial in a community-based teaching hospital in eastern Nepal. JSLS 2007;11:358-62.

23. Hernandez JM, Morton CA, Ross S, Albrink M, Rosemurgy AS. Laparoendoscopic single site cholecystectomy: the first 100 patients. Am Surg 2009;75:681-5.
24. Ramachandran CS, Arora V. Two-port laparoscopic cholecystectomy: an innovative new method for gallbladder removal. J Laparoendosc Adv Surg Tech A 1998;8:303-8.

25. Bisgaard T, Klarskov B, Rosenberg J, Kehlet H. Characteristics and prediction of early pain after laparoscopic cholecystectomy. Pain 2001;90:261-9.

26. Philipp SR, Miedema BW, Thaler K. Single-incision laparoscopic cholecystectomy using conventional instruments: early experience in comparison with the gold standard. J Am Coll Surg 2009;209:632-7.

27. Sajid MS, Ladwa N, Kalra L, Hutson KK, Singh KK, Sayegh M. Single-incision laparoscopic cholecystectomy versus conventional laparoscopic cholecystectomy: meta-analysis and systematic review of randomized controlled trials. World $\mathrm{J}$ Surg 2012;36:2644-53. 